\title{
Skills and knowledge needs assessment of current and future library professionals in the State of Qatar
}

\begin{abstract}
Purpose

The purpose of this research was to investigate and document the skills and knowledge needs of future library professionals in Qatar and to use the outcomes of this research to help develop or refine focused library and information studies course curricula that meet the needs of the local workforce and also guide or improve national or local professional development programmes.
\end{abstract}

\section{Design/methodology/approach}

A skills and knowledge needs assessment survey was sent to library professionals, LIS students and library managers in Qatar. A total of 109 respondents completed the survey, a representation of around 25\% of the current LIS workforce in Qatar.

\section{Findings}

Findings indicated that respondents felt that the most needed future job roles included more client focused positions such as research librarians, information services librarians and subject librarians, as well as technical roles such as Arabic cataloguers, electronic resources librarians and system librarians. The largest amount of needed positions was also felt to be in school libraries. Respondents to the survey also felt that there was a lack of opportunities for professional development in Qatar and that the most needed area of skills training was information literacy, followed by copyright training and technical skills including RDA and Arabic cataloguing. One further finding identified from the survey was the concern felt by respondents about the lack of a professional body in Qatar that represented LIS professionals.

\section{Practical implications}

This paper provides data on future roles, skills and knowledge needed by library professionals working in international and culturally diverse workforces. It also provides findings that can be used to develop LIS curriculum and professional development programmes in international LIS environments.

\section{Originality/value}

A detailed needs assessment of this kind has not previously been undertaken in Qatar. The library and information sector in Qatar is an emerging field with a largely international workforce. This situation provides a distinct perspective on the needs of an emerging library sector that is a blend of different cultures, workplace practices and differing expectations and understandings of the role and skills needed to be a LIS professional. 


\section{Background}

The profession of librarianship in the State of Qatar is currently in a phase of rapid growth, development and transition. The creation of the Qatar National Library, scheduled to open in 2015, aims to preserve the rich archival heritage of Qatar and the cultural legacy of the Arab World and places libraries and librarianship at the forefront of the country's future plan. In addition, a number of other new academic and special libraries have also recently opened or are scheduled to open in the next few years. To help support these developments and meet the need for an increasing number of future Qatari library professionals University College London - Qatar (UCL Qatar), in partnership with Qatar Foundation and Hamad Bin Khalifa University, commenced a new MA programme in Library and Information Studies in October 2013, the first such postgraduate programme to be delivered in the country.

Qatar's current workforce is made up of a number of people from different expatriate populations and is reliant on imported knowledge and skills from an international workforce, especially due to its current rapid growth and lack of a local workforce that can fill skilled positions. This is also true in the LIS sector where currently the majority of the workforce is from Western countries, such as the USA and UK, along with LIS professionals from other Arab countries such as Egypt. This survey indicated that only around 10\% of respondents were Qatari, which is not surprising as the library profession in Qatar is still emerging and as such there are still comparatively few qualified and experienced Qatari librarians. This situation provides some distinct challenges when it comes to developing appropriate LIS curriculum and professional development courses for an international diverse and often transient workforce. In order to successfully meet the specific local needs of library professionals and libraries both now and in the future, it was important to first investigate the background and needs of the library professionals in Qatar, especially in terms of specialised or local requirements.

The LIS profession in Qatar offers distinct perspectives on the needs of an emerging library sector that is a blend of different cultures, workplace practices and differing expectations and understandings of the role and skills needed to be a LIS professional. Therefore, this paper provides a significant contribution to research conducted on future roles, skills and knowledge needed by library professionals both now and in the future. This is especially relevant as there is a growing interest in internationalization, both in LIS curriculums and in the profession more widely, in order to improve curriculums and to understand the nature of the LIS profession (Gerolimos 2009).

\section{Literature Review}

Recent discussions regarding the skills needed by library professionals have focused on a number of factors including employer needs, generic skills versus specific skills and the competencies needed by librarians working in more information technology or digital environments. Buarki, Hepworth \& Murray (2011), note that the trend of LIS programmes has been to shift the emphasis from 'library' to 'information'. However, despite this trend of integrating more information technology or digital courses into LIS programmes, research suggests that although there is an emphasis on technical skills and knowledge in today's digital environment, traditional LIS skills are still sought and needed in the library and information profession. (Chow, Shaw, Gwynn, Martensen, \& Howard, 2011; Stephens, D \& Hamblin, 2006). There is also some research that suggests that employers may be more concerned with soft or generic skills such as analytical ability and communications skills, customer service skills, business and marketing skills, flexibility, and adaptability rather than 
on traditional technical skills, some of which employers feel can be learnt on the job, and that employers place great importance on experience, which in turn means that LIS programmes may need to emphasis internships, networking, mentoring, and leadership skills (Choi \& Rasmussen, 2009; Chow, Shaw, Gwynn, Martensen, \& Howard, 2011; Nonthacumjane, 2011).

Several articles in the literature focus on what skills and qualifications are important for the profession based on job advertisements. Choi \& Rasmussen (2009) analysed job advertisements for digital library positions over an eight year period and found that there was a need for professionals to have current awareness of appropriate technological skills, knowledge of metadata and management skills. Their analysis of the job advertisements also confirmed that there is a demand for generic skills such as project management, teamwork and interpersonal skills. Gerolimos \& Konsta (2008) analysed 200 job advertisements from the UK, Canada, USA and Australia in 2006 and 2007 in order to identify skills and qualifications required by the library profession. Overall, they identified 38 skills and qualifications including again that generic skills such as communication and interpersonal skills were highly sought after for library professionals. They also found that job advertisements often mentioned positions that required the development of digital collections and the ability to adapt current skills to meet the demand of new practices in modern information environments. In a similar study that analysed job advertisements in Australia the authors also found that interpersonal and behavioural skills were the most frequently required skill for LIS professionals (Wise, Henninger \& Kennan, 2011). The authors also found that traditional skills like cataloguing, collection management, knowledge of metadata and database management were also highly sought after. Conclusions can be drawn from these studies and job advertisements that although technical and specific skills are required for LIS jobs, employers are more concerned that LIS professionals have the skills needed to work in a rapidly changing environment and that traditional skills are still sought after but the nature of these skills have changed to include technical aspects.

The changing roles and skills and knowledge needed by librarians in the future is also a prevalent issue discussed in the literature. Nonthacumjane (2011) discusses what skills and competencies are required for LIS professionals in the digital era through the content analysis of literature in this area. The author found that library professionals in the digital era were required to be analytical, creative and flexible, have general skills such as communication and teamwork and critical thinking and more technical skills such as knowledge of collection development, digital library software and metadata. Haddow (2012) conducted a survey of current and future skills needed by reference librarians in Australia and found that online searching skills was considered to be the most important technical skill needed for today's reference librarians with web design, use of social media and software troubleshooting all considered to be important technical skills in the future. As with other studies (Ashcroft, 2004; Chow, Shaw, Gwynn, Martensen, \& Howard, 2011), communication, adaptability and flexibility were again considered to be important skills needed both now and in the future by librarians.

Another significant area discussed in the literature is what specific skills LIS employers need in the workplace and if LIS programmes are providing relevant and appropriate training to LIS students. Stephens \& Hamblin (2006) found that there is a continuing need from employers for graduates with the core skills of the profession such as collection management and organisation of information. The study also found that recent library graduates in the UK did not possess some skills required by some employers, such as information retrieval, use of information for business and generic skills, such as persuasion and how to apply theories learnt in class in a practical situation. Gerolimos (2009) also studied what qualifications or skills are being taught in LIS degrees in the US, Canada and the UK through analysis of their programmes. The author concludes that a curriculum that incorporates courses that are traditional but also focuses on issues pertaining to digital technologies gives LIS students the 
best option to obtain suitable qualifications for the current library environment. The author also found that there has been some effort to develop generic and social skills in LIS programmes, an important issue as research seems to suggest that these skills are valued by employers.

Rehman and Marouf (2007) surveyed LIS graduates at a programme in Kuwait and found that while they were in general satisfied with the core elements of the programme they noted that the elective component did not allow for enough opportunity to specialize or offer subjects in core critical practice. This is an interesting point to note, however the article fails to further discuss which areas the students would have liked to have received more training in, however the authors stated that although the course had added subjects about digital libraries, the content was not necessarily up to date. Another study conducted at one LIS school in the US, to investigate if LIS curriculum is being delivered that teaches skills and knowledge to equip students in a rapidly changing environment, found that in general library managers were satisfied with the skills of graduates from the LIS programme (Chow, Shaw, Gwynn, Martensen, \& Howard, 2011). The study also found that the most successful skills managers were looking for were more general skills such as communication and that some skills such as cataloguing were seen as skills that could be learnt on the job. These studies clearly show that employers are looking for LIS graduates that have skills and knowledge of both general skills and specific LIS skills and knowledge, but most importantly that graduates can be flexible and adaptable in the constantly changing digital environment.

\section{Methodology}

A survey was sent to library professionals, LIS students and library managers in Qatar. This survey was based on the Nexus Census survey conducted in Australia. (Hallam, 2008). The survey contained 43 questions, comprising a mixture of open, closed, multiple-choice and matrix questions. However, the number of questions each respondent was asked to answer varied according to their qualification status, employment status and job role. Questions were predominantly quantitative in nature, although supplementary qualitative feedback was also sought for certain questions. All issues studied in the survey were attributed to one of five broad categories, each of which was selected to ensure a coherent and comprehensive analysis of the current and future state of the library profession across the State of Qatar. These five categories were: Demographic data; Educational status; Employment information; Professional skills; Professional development. Comparative analysis of the data collected from the questions in each of these five categories was also undertaken in order to identify any trends, relationships, differences or similarities in the data and in so doing gain a better understanding of any important causal issues or contributory factors.

\section{Discussion of Findings}

In total, 109 respondents responded to the survey. Based on an analysis of staff information for libraries obtained from the Qatar National Library Directory of Libraries in Qatar, it is estimated that the total number of survey respondents $(n=109)$ represents approximately $25 \%$ of the total library workforce currently (as of 2014) based in Qatar.

\section{Background Information}

\section{Nationality}

The results of this question were quite clear with an overwhelming majority of respondents hailing from the United States (21\%), followed by the United Kingdom (16\%). The next most 
populous group by nationality were Qataris, numbering $10 \%$ of respondents, with Canadians and Egyptians ranking joint fourth with 9\% of respondents each.

The fact that the two largest respondent groups were from the United States and United Kingdom is not surprising and most probably links to the point mentioned above regarding the need for Qatar to fill a significant number of core professional library post from countries such as the United States and the United Kingdom where there are large numbers of suitably qualified and experienced librarians who speak English as a first language. That only $10 \%$ of respondents were Qatari at first glance appears surprising, given that many libraries in Qatar have been actively trying to recruit Qatari librarians. However, this is perhaps to be expected given that the library profession in Qatar is still emerging and that there are still comparatively few qualified and experienced Qatari librarians.

\section{Employment Information}

\section{Current Landscape - Type of Library Services}

The research data confirms that the educational sector in Qatar contains the highest proportion of librarians with $46 \%$ of respondents stating that they work in a university library and $26 \%$ of respondents stating that they work in a school library. This compares with only $8 \%$ who work for the National Library, $7 \%$ who work for public libraries, and $7 \%$ who work for special libraries in government departments (see Figure 1).

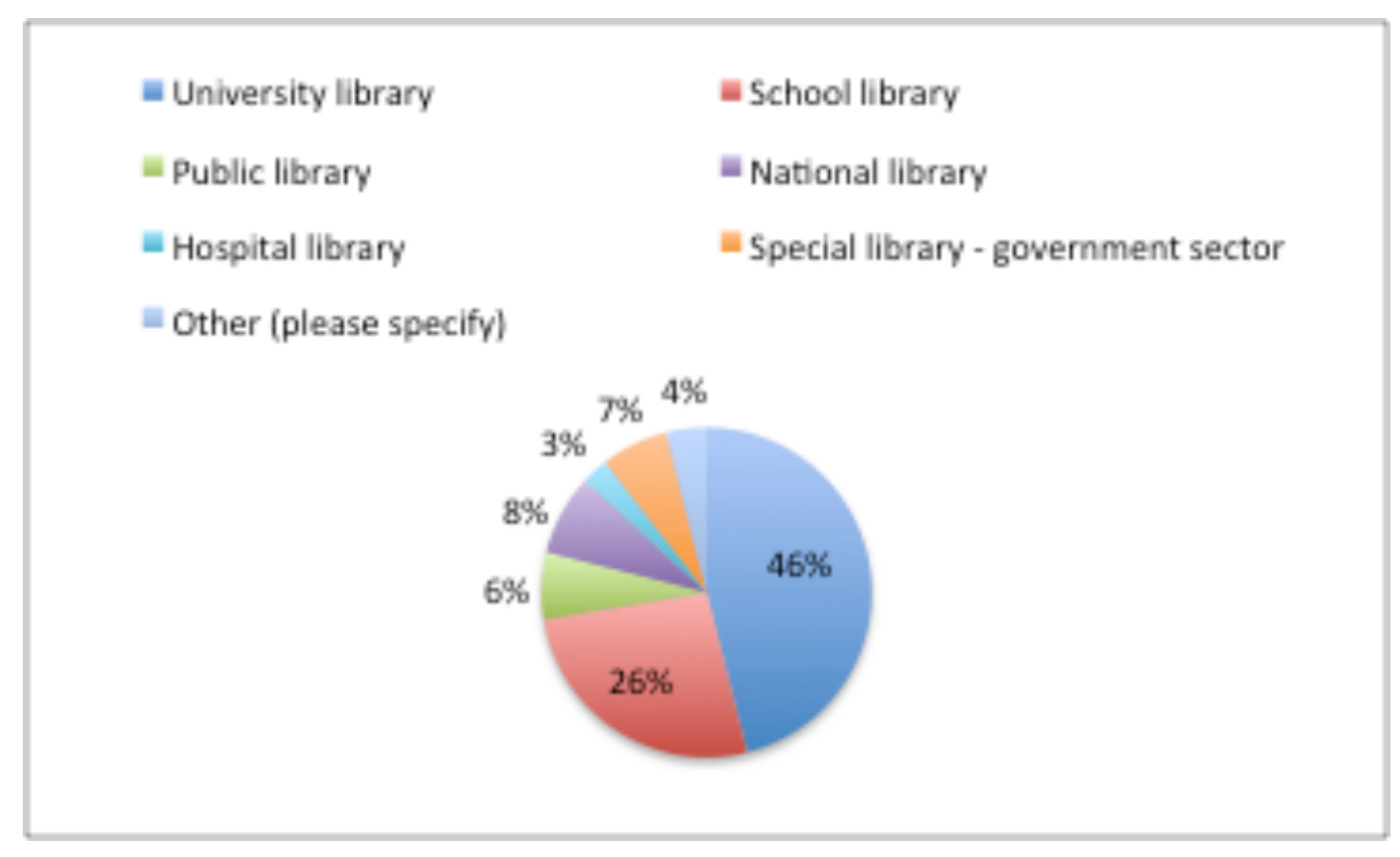

Figure 1 - Employment Distribution by Library or Information Service Type

\section{Current Landscape - Library Staffing Numbers}

One distinctive feature of the question that examined current staffing numbers in Qatari libraries is that most respondents currently work in relatively small libraries. 39\% of the respondents (the largest category) worked in libraries that had less than five staff as compared to just $3 \%$ who worked in libraries with more than 50 staff (the smallest category). 
This possibly reflects the emerging nature of the profession in Qatar with many libraries, particularly university libraries, having only been established within the last ten to fifteen years and in most cases only catering for comparatively small user populations.

\section{Current Landscape - Length of Employment}

The results of this question pointed towards the library workforce in Qatar being relatively new and in the process of developing as the majority of respondents stated that they had been in their jobs for two years or less, with $19 \%$ having been in post for less than one year and $21 \%$ for between one and two years. Only $9 \%$ of the workforce stated that they had been in their current posts for more than ten years.

Interestingly though, $21 \%$ of respondents stated that they had worked in their current positions for between five and ten years, which would indicate that whilst the workforce might be relatively new, it is nevertheless not completely new and has developed to some degree (see Figure 2).

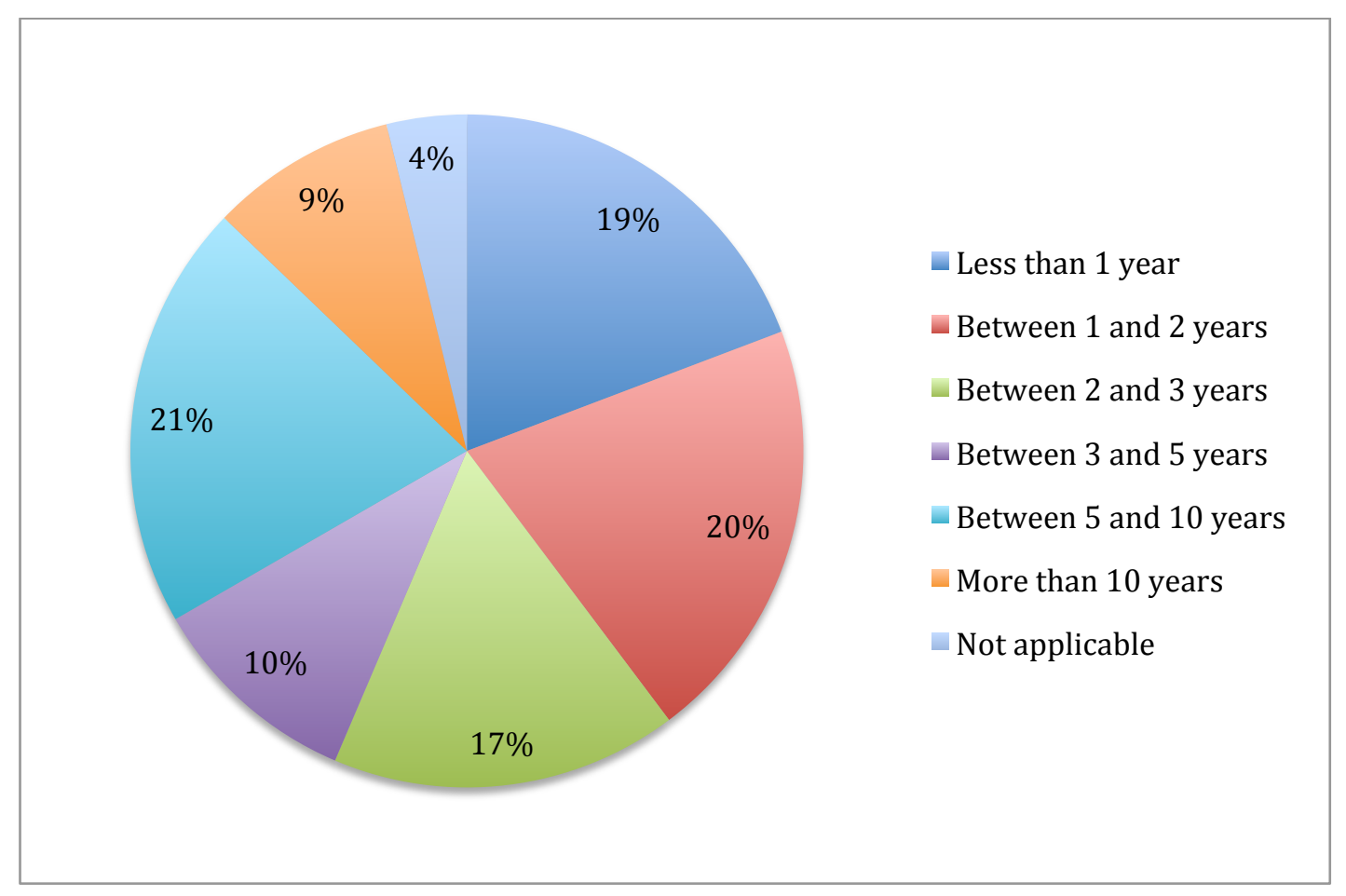

Figure 2 - Length of Time in Current Position of Employment

\section{Future Landscape - Job Roles Required}

A critical aspect of the research survey was the investigation of future employment needs and requirements for the library profession in Qatar. Respondents were asked to consider a set list of library and information job roles and to select which ones they felt were most critical to the future development of the library and information services sector in Qatar. Respondents were allowed to pick as many options as they wanted.

There was an acknowledgement that job roles that required direct collaboration and interaction with library users would be increasingly needed in the future. Three job titles were selected as being particularly needed in this respect, with 'Research Librarian' being selected 
by $72 \%$ of respondents, 'Information Services Librarian' being selected by $70 \%$ of respondents, and 'Liaison / Subject Librarian' being selected by $65 \%$ of respondents.

One notable finding was that certain skilled technical library positions were clustered together at the 'most needed' end of the scale, whereas other skilled technical positions were clustered together nearer to the 'least needed' end of the scale. Those scoring highly in terms of being most needed included roles such as 'Arabic Language Cataloguer' (70\%), 'Digital Content / Electronic Resources Librarian' (68\%), and Systems Librarian (68\%). Those with lower scores included 'English Language Cataloguer' (56\%), 'Special Collections Librarian' (54\%), 'Book / Paper Conservator' (35\%). This seems to reflect an anticipated shift to an increasingly digital / electronic dominated library work environment and to an environment where the needs of the local, Arabic speaking population will need to be given far greater prominence.

Other interesting findings from the data indicated that more librarians would be needed for certain specific sectors with school librarians featuring prominently with $75 \%$ of respondents selecting this as the most needed future job role in Qatar. This was in fact the highest rated job role of all those that were listed.

The supplementary comments that were received for this question also seemed to support the above narrative with several respondents stating that librarians with information literacy and instruction job roles would be very important for the future profession in Qatar, particularly in school and academic libraries. One respondent stated that 'Information Literacy teaching librarians is a must' whereas another noted that 'Information literacy and instruction librarians are the most important role for school and academic libraries'.

In relation to the future need for librarians working in schools, one respondent observed that there was an urgent need for specially trained children's and teen service librarians. The respondent pointed out that this is a 'core user group' and that there was currently a 'lack of courses for children's librarians, teen librarians, and school librarians in regard to their specialized programmes, services and collections'.

Regarding the future need to focus more on the requirements of the local, Arabic speaking population, which was borne out by the high score for Arabic language cataloguers, one respondent stressed that there was a definite need for 'Arabic speaking reference librarians'. Finally, when comparing future job roles with the sector breakdown of libraries that respondents work for (see Figure 3), it can be seen that the job roles that have been selected as most needed are distributed fairly evenly across different library sectors with a relatively even pattern emerging that is in direct proportion to the number of respondents working across each different library sector. 


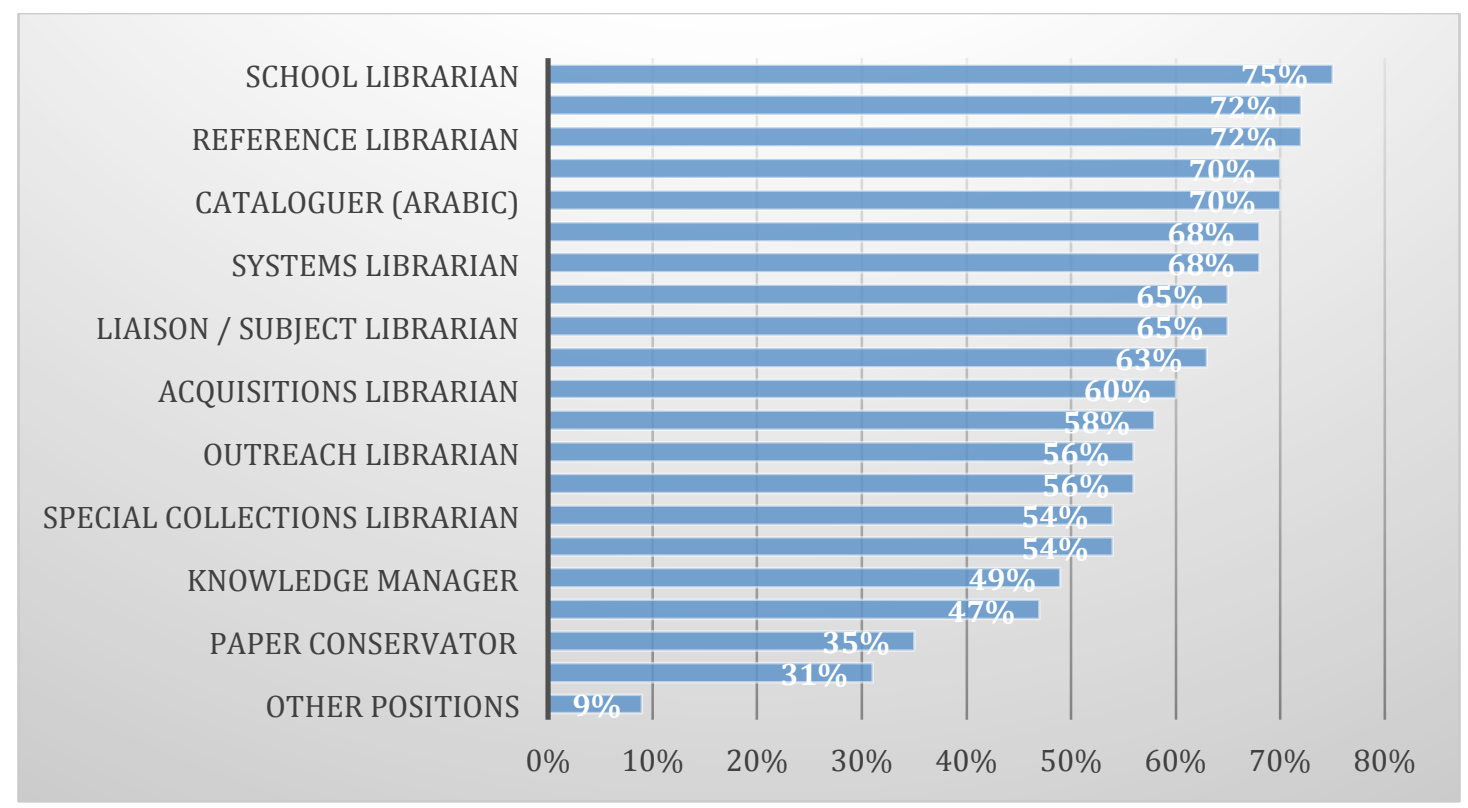

Figure 3 - Breakdown of Future Job Roles Needed by Library Sector Type

\section{Future Library Staffing Requirements}

Library managers and directors were asked to predict how many positions and what type of positions they would probably need to recruit for their libraries over the next five years. The overwhelming majority of respondents $(67 \%)$ stated that they would need to recruit between one and five positions. This was followed by those stating they would need to recruit between six and ten positions (14\%). This again points towards the fact that most libraries in Qatar are relatively small in nature when compared to libraries in many other countries and that their development needs are fairly contained and specific. The majority of respondents seeking to recruit between one to five staff over the next five years work in academic or school libraries, whereas the majority of those seeking to recruit between six to ten work staff work in hospital libraries or the Qatar National Library, which is scheduled to open in 2015. This reflects the rapid expansion and development of infrastructure across both of those areas within Qatar over the next five year timeframe.

In terms of the types of positions that library directors and managers felt would be needed, the majority of respondents selecting subject liaison, reference, or instructional librarian type roles as being those that they would need to recruit.

Similarly, the need for librarians with Arabic language and/or Arabic cataloguing skills was mentioned by several respondents. The need for digital librarian type roles was also noted by three respondents, which matched the findings from the previous question.

Library managers also indicated that there was the need for research data managers or data curators. Three respondents listed these as being positions that they would need to recruit during the next five years, signifying perhaps a gradual move towards the future provision of more specialist and/or more quantifiably value-added support for library users within Qatari libraries.

\section{Professional Skills}

This section of the survey examined the current professional skills and knowledge needs of the library workforce in Qatar, focusing in particular on how essential specific skills and knowledge areas are in the library profession in Qatar both now and in the future. 
Two questions were asked in this section - one concerning the relative importance of predefined core library skills and knowledge in the workplace and the other concerning the need for other types of skills and knowledge.

The findings from these questions provided an in-depth understanding of the current professional landscape within Qatar libraries and of the areas where most activity is currently being focused. Furthermore, it also highlighted areas in need of growth and development.

\section{Essential Skills and Knowledge for Library Positions in Qatar}

A list of predefined library skills and knowledge, including both technical and soft skills, were listed and respondents were asked to select which ones they felt were most essential for library positions in Qatar at present. Respondents were invited to select multiple options if they so wished.

The top six selected themes in the 'Absolutely Essential' category, together with the percentage of respondents selecting each theme, were as follows:

1. Reference and enquiry services $-72 \%$

2. Information support to students $-72 \%$

3. Information literacy instruction $-72 \%$

4. Collection development and management $-57 \%$

5. Marketing of library services $-54 \%$

6. Policies and procedures development $-51 \%$

This denotes the importance of core library service development and support activities which are critical for all libraries in Qatar, as well as the importance of specific activities such as information literacy instruction that are critical to certain types of libraries only, mainly academic libraries.

Themes that did not feature prominently in either the 'Absolutely Essential' or 'Very Essential' categories included activities such as binding of materials, conservation of library resources, writing grant proposals, and digital humanities activities.

\section{Other Types of Essential Skills and Knowledge for Library Positions in Qatar}

Other skills and knowledge areas that were considered to be essential for library staff in Qatar included a mixture of soft skills, technical skills, and local knowledge.

Soft skills that were specifically mentioned included presentation skills, communication skills and time management. Technical skills that were mentioned included ICT skills and digital archiving skills, and local knowledge that was seen as important included awareness of Qatari heritage and culture and Arabic language skills.

\section{Professional Development}

The final section focused on the current and anticipated future professional development needs of the library workforce in Qatar.

Five distinct areas were examined - professional development courses currently required in Qatar, satisfaction with current professional development provision, professional development workshops, events and conferences needed in Qatar, the need for a professional library body in Qatar, and specific future skills or knowledge areas that need to be developed within the Qatar library workforce. 
This data helped to inform the wider picture for the library profession in Qatar by examining the ways in which librarians were developing within the workplace and, critically, where gaps existed that needed to be filled in terms of the acquisition of professional skills and knowledge.

\section{Current Professional Development Course Requirements in Qatar}

Six courses were nominated as being particularly important for the current professional development of librarians in Qatar. These reflected a mixture of both hard and soft skills professional development training.

As can be seen from Figure 4, information literacy is currently seen as the most important area for librarians in Qatar in terms of their professional development requirements, with 77\% of respondents selecting this option. This was reinforced by a range of comments emphasising the need for information literacy skills development. This was followed by copyright training, which was selected by $66 \%$, and management and leadership development, which was selected by $61 \%$ of respondents.

Specific technical skills also featured prominently in the list of professional development courses currently being sought. RDA and Arabic cataloguing were the highest scoring selections in this respect with $58 \%$ of respondents selecting RDA and 56\% selecting Arabic cataloguing.

This data confirms that there is much demand and a continuing need for both core library skills development training as well as specialist technical training. Furthermore, it points towards a need for national / regional specific training, as is the case with Arabic cataloguing and also copyright, which for the purposes of this survey relates to Qatari copyright legislation. Most importantly of all though it is clear that these results, point towards an insufficient supply of professional development training across a wide spectrum of activity areas in Qatar.

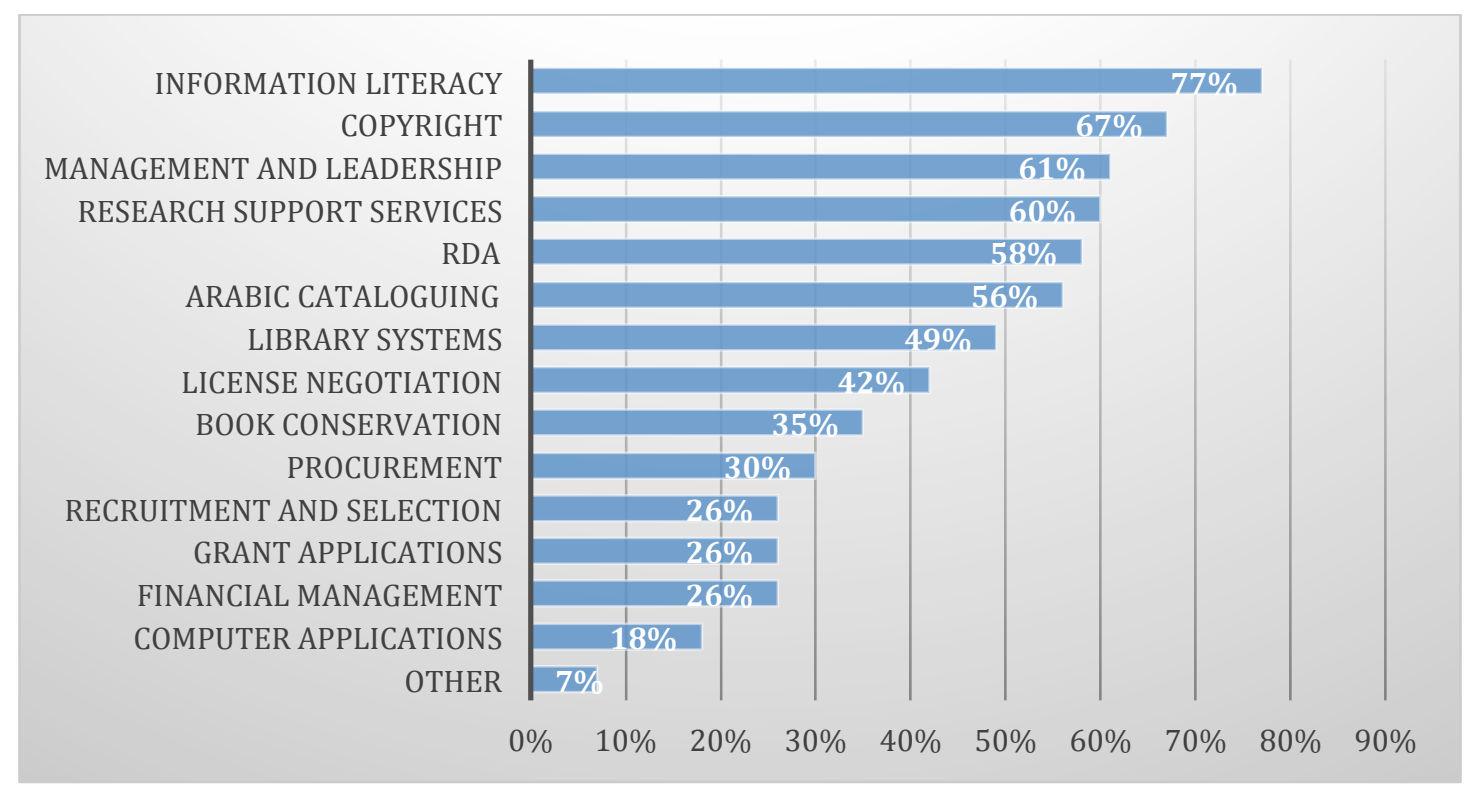

Figure 4 - Short Courses or Professional Development Currently Needed in Qatar 


\section{Satisfaction with Current Professional Development Provision}

The results of this question reflected and reinforced the above conclusion that insufficient professional development training is readily available at present, as $58 \%$ of respondents stated that they were not satisfied with the level of professional development opportunities that were available to them in Qatar, as opposed to $18 \%$ who were satisfied. $24 \%$ stated that they were not sure.

For those respondents not satisfied, the most frequently cited reason for this group was the sheer lack of available professional development support in Qatar, with a number of respondents stating that they had to travel to other countries to receive training.

Comments on this subject included the following: 'There are none! The conferences are more about showing research output from academics rather than practical skills development', whilst another stated 'because there are so few, I attend everything, even if it isn't relevant. Some PD events aren't relevant'. Similarly, another respondent noted 'we have to travel outside for professional development or study on our own'.

Three respondents noted that the Arabian Gulf Chapter of the Special Libraries Association and also the Information Literacy Network offered some professional development opportunities, although these were mainly conferences of the type noted in the comment above, and as such training frequently had to be sought elsewhere. One respondent noted ' $I$ rely on web-based training / PD and international travel as there is not much professional development in Qatar itself.'

The relatively small size of the library workforce in Qatar was noted as a contributory factor in the lack of professional development training opportunities with one person observing that 'The professional community is fairly small and while experts are brought into the region on occasion, it is still necessary to go abroad in order to participate with a larger group of professionals in each library category'.

As well as noting the lack of professional development training opportunities for the library workforce as a whole, a number of respondents also pinpointed the lack of opportunities for specific library sectors, with school libraries featuring prominently in this respect. One respondent stated that 'Schools, I have found, appear to be left out in the cold laying preference to university libraries, making us all feel excluded and less valued as a learning provider' whilst another respondent observed that 'There are professional development opportunities, but I often feel as if they do not cater to the K-12 school librarian. Often they are geared towards university librarians.' Three other very similar comments were also received, pointing to the fact that school librarians in Qatar believe that their professional development needs are currently not being met at all.

Of the $18 \%$ of respondents who were satisfied with the professional development training opportunities on offer, most pointed out their satisfaction with the opportunities that were provided to them by their employer to attend training events rather than with the provision of professional development training in Qatar per se. A typical comment received was 'I have the money and professional support to go to training sessions almost anywhere in the world, often enough.'. Only one comment in the 'satisfied' section reflected a sense of contentment with current professional development training opportunities in Qatar, which, as with the comments indicating a lack of satisfaction, point towards a real dearth of professional development support for librarians in Qatar at the current time. 


\section{Professional Events, Workshops and Conferences Needed in Qatar}

In a similar vein to the previous question about professional development course requirements, respondents were also asked to consider what professional development events, workshops and conferences were needed in Qatar.

As with professional development course requirements, information literacy, copyright and Arabic cataloguing were the most frequently selected themes for professional events, workshops and conferences. Of these information literacy was the most frequently cited requirement with eight respondents mentioning this as an area of need. Teaching skills for information literacy, as opposed to information literacy more generally, were also specifically mentioned by two separate respondents.

Other themes that were mentioned by at least one respondent as being required areas for professional development events and workshops in Qatar included library systems and technologies, Marc 21, RDA, digitisation, and marketing.

\section{Need for a Professional Library Body in Qatar}

When asked if a professional library body or association, such as CILIP or ALA, was needed for Qatar an overwhelming majority of respondents - 80\% - stated that this was a requirement. Only $2 \%$ disagreed and $18 \%$ were not sure. This is a strong endorsement of the need for some kind of professional representation in Qatar, and the comments that were received from respondents on this topic reinforced these statistics.

Most of the comments received stated that a professional body or association was need for two main reasons - to support librarians working in Qatar and to help grow and develop the profession in Qatar.

Reasons given by respondents as to why a professional association was needed to support the library workforce in Qatar included: 'to better meet the needs of librarians', 'to keep librarians up to date in their field', and 'libraries play a key role and should have a professional association to regularly organize professionals and provide some continuing education.'

Reasons given for why a professional association was needed to help grow and develop the profession included: 'to ensure that the library culture in Qatar continues to grow and develop professionally, and to develop and facilitate cooperation between all library entities in the country' and 'to represent and promote the profession and contribute to a better understanding of the necessity of librarianship to education and research and improvements in individuals social and economic spheres.'

Other reasons cited included the need for co-ordination of professional networking and communication, to help manage professional development, to provide training and workshops, and to exchange good practice. There was also acknowledgement of the need for an association to help preserve Arabic literary culture and heritage and also for a professional association, perhaps one that operates in tandem with Qatar National Library, to be involved in the establishment of a national library strategy and of national standards.

\section{Conclusion}

The state of the LIS profession in Qatar is, like the country as a whole, currently experiencing a period of rapid growth and development. This research has shown that there are two key areas that need to be given particular prominence by LIS educators and managers. The first 
area relates to the noticeable shortfall within the current Qatar LIS workforce and amongst those who are entering the workforce in terms of the level of skills and knowledge needed to fill the types of specialist roles that are increasingly required in most LIS workplaces. The second area relates to the dearth of local professional development training opportunities and the associated lack of an overarching professional association or body to co-ordinate and manage all professional development activities across the country, or even across the Gulf region more broadly.

In terms of the technical skills and knowledge gaps that were identified in this research, it would appear that few librarians in Qatar consider themselves to be sufficiently knowledgeable of many of the core technical competencies of relevance to the LIS workplace. This was borne out by the high number of respondents who cited the need to attend professional development courses, workshops or conferences on the subject of technical subjects such as RDA and cataloguing above any other type of professional development training. There was also acknowledgement in the data of a demonstrable need for more technical capacity within the workforce as a whole with technical roles of all kinds being identified as being among the most needed roles for Qatar libraries now and in the future, and being identified as the types of roles for which library managers would most like to recruit staff.

In terms of soft skills gaps, as with the literature more broadly the main findings from the research were that there was a strong need for more library staff in Qatar with the ability to undertake the types of roles that involved direct communication and interaction with library users, especially from an instructional or liaison standpoint. This was made clear in the results of the survey in terms of the focus on the need for further growth, development and professional support for those areas of work that link to information literacy instruction or subject support work. The importance of these soft skills was further reinforced by the fact that survey respondents identified these types of skills, especially information literacy skills, as being the most important for library staff to be aware of in the LIS workplace and as being the areas of professional development that they personally felt were most important for them to acquire. It was also interesting to note that information literacy was the most developed of all the professional skills areas in terms of the level of professional support that was currently available in Qatar and across the Gulf region more broadly with the Information Literacy Network being widely seen by survey respondents as an example of a highly effective and informative professional development group.

These findings indicate that library professionals in Qatar see a need for skills and knowledge in both current and future job roles in more client focused traditional library roles and also emerging and specialised technical roles. Curriculum in the LIS programme and short course programmes in Qatar is continuously evolving to reflect the diverse professional needs of LIS professionals in the region. 


\section{References}

Ashcroft, L. (2004), "Developing competencies, critical analysis and personal transferable skills in future information professionals", Library Review, Vol. 53 No. 2, pp. 82-88.

Buarki, H., Hepworth, M., \& Murray, I. (2011), "ICT skills and employability needs at the LIS programme Kuwait: a literature review", New Library World, Vol. 112 No. 11/12, pp. 499-512.

Choi, Y., \& Rasmussen, E. (2009), "What qualifications and skills are important for digital librarian positions in academic libraries? A job advertisement analysis", The Journal of Academic Librarianship, Vol. 35 No. 5, pp. 457-467.

Chow, A. S., Shaw, T. L., Gwynn, D., Martensen, D., \& Howard, M. (2011), “Changing Times and Requirements: Implications for LIS Education", LIBRES: Library \& Information Science Research Electronic Journal, Vol. 21 No. 1.

Gerolimos, M. (2009), "Skills developed through library and information science education", Library Review, Vol. 58, No. 7, pp. 527-540.

Gerolimos, M., \& Konsta, R. (2008), "Librarians' skills and qualifications in a modern informational environment", Library Management, Vol. 29 No. 8/9, pp. 691-699.

Haddow, G. (2012), "Knowledge, skills and attributes for academic reference librarians", Australian Academic \& Research Libraries, Vol. 43 No. 3, pp. 231-248.

Hallam, Gillian C, (2008), "Nexus: An investigation into the library and information services workforce in Australia. Final Report."

Nonthacumjane, P. (2011), "Key skills and competencies of a new generation of LIS professionals", IFLA Journal, Vol. 37 No. 4, pp. 280-288.

Rehman, S., \& Marouf, L. (2008), "MLIS program at Kuwait University: perceptions and reflections", Library Review, Vol. 57 No. 1, pp. 13-24.

Stephens, D., \& Hamblin, Y. (2006), "Employability skills: are UK LIM departments meeting employment needs?: The results of a survey of employment agencies identifies gaps in UK LIM curricula in the UK", New Library World, Vol. 107, No. 5/6, pp. 218-227.

Wise, S., Henninger, M., \& Kennan, M. A. (2011), "Changing trends in LIS job advertisements", Australian Academic \& Research Libraries, Vol. 42 No. 4, pp. 268-295. 